\title{
Agronomic traits, photosynthesis and gas exchange variables of wheat genotypes in response to water deficit during vegetative growth period
}

\author{
Shiva Ardalani' ${ }^{1}$, Mohsen Saeidi ${ }^{*}$, Majid Abdoli ${ }^{2}$ \\ ${ }^{1}$ Department of Agronomy and Plant Breeding, Campus of Agriculture and Natural Resources, Razi University, Kermanshah, Iran \\ ${ }^{2}$ Young Researchers and Elite Club, Zanjan Branch, Islamic Azad University, Zanjan, Iran \\ ${ }^{\star}$ Corresponding author, E-mail: saeidi_mohsen@yahoo.com
}

\begin{abstract}
Water stress is the main environmental stresses that affects agricultural production worldwide, especially in arid and semi-arid regions. This study was designed to evaluate the effects of water deficit during the vegetative stage on gas exchange variables and their relationship with water use efficiency and grain yield formation of wheat. A factorial pot experiment was carried out in complete randomized block design with three replications in greenhouse with two water regimes (well-watered and water deficit at vegetative growth stage). The bread wheat genotypes 'Pishtaz,' 'DN-11', 'Sivand' and 'Marvdasht' were used. Analysis of variance revealed significant differences between water regimes and among the genotypes for most traits. The results showed that water deficit decreased net photosynthetic rate, transpiration rate and stomatal conductance, but caused no change in photosynthetic sub-stomatal $\mathrm{CO}_{2}$ concentration and water use efficiency. Thus leaf temperature of wheat was higher with water deficit, compared to that of the control. In addition, water deficit stress reduced leaf area, grain yield, water use efficiency and evapotranspiration efficiency by $39.7,54.4,31.8$ and $32.4 \%$, respectively in all genotypes. Water deficit reduced yield per plant significantly with a decrease in leaf area and net photosynthetic rate. The 'Marvdasht' genotype exhibited comparatively more tolerance to drought in the vegetative growth stage with less decline in agronomic traits and gas exchange variables, compared with other genotypes. In conclusion, physiological and agronomic traits of wheat significantly decreased due to interrupted irrigation at the vegetative stage in comparison with fully watered status.
\end{abstract}

Key words: bread wheat, grain yield, photosynthesis, Triticum aestivum, vegetative stage, water deficit. Abbreviations: PWUE, photosynthetic water use efficiency; WUE, water use efficiency.

\section{Introduction}

Bread wheat (Triticum aestivum L.) is the main food in the world (Gourdji et al. 2013), and as a staple food ranks first among the cereal crops in Iran. Environmental stress, such as water deficit, can be a primary cause of crop loss worldwide, leading to average yield losses of over 50\% for major crops each year (Chaves, Oliveira 2004). Water deficit is that the most important limiting factor for growth and yield of crop plants, especially regarding wheat in arid and semiarid regions around the world (Powell et al. 2012). To survive under water stress, plants have evolved morphological, physiological, and biochemical responses.

Water deficit in plants is caused by higher water loss through stomata; therefore the majority of plants are vulnerable to water deficit conditions. Water deficit stress might cause plant senescence and death and additionally reduced crop production, because excess accumulation of reactive oxygen species results in lipid peroxidation, plasma membrane injury and chlorophyll degradation, and reduced leaf area due to reduced cell development (Mukherjee, Choudhuri 1983; Lawlor, Tezara 2009). Also, stomata closure leads to reduction of sub-stomatal $\mathrm{CO}_{2}$ concentration in leaves and subsequent decrease in the net photosynthesis rate during water deficit stress conditions (Chaves et al. 2002; Talebi et al. 2013). In turn, these events can lead to decreased crop yield.

Knowledge of relationship between yield components and grain yield can aid producers in crop management by focusing on key yield components. The most sensitive stage of winter wheat to water stress is from stem elongation to booting, followed by flowering (Zhang et al. 2003). Reduced yield in response to water deficit during the reproductive period has been reported in several studies (Inoue et al. 2004; Pradhan et al. 2012; Azhand et al. 2015; Cui et al. 2015), whereas the effects of water deficit during the vegetative period on yield remain unclear.

In the present study, we analyzed gas exchange variables and some agronomic and physiological traits involved in the response of contrasting wheat genotypes to water deficit. Our objectives were to study the effects of water deficit during vegetative periods on grain yield, the photosynthetic capacity of leaves, and to clarify the relationship between grain yield and photosynthetic 
capacity in different wheat genotypes. The results of this study provide valuable information that can be used as the genetic basis of improvement of wheat to enhance yield under stress conditions.

\section{Materials and methods}

\section{Plant material and growth conditions}

A pot experiment was carried out during the growing season from 2011 to 2012 in the greenhouse of Campus of Agricultural and Natural Resource, Razi University in Kermanshah city in western Iran $\left(47^{\circ} 9^{\prime} \mathrm{E}, 34^{\circ} 21^{\prime} \mathrm{N}\right.$; $1319 \mathrm{~m}$ elevation from sea level). The climate based on the Domarten classification in the study area is semiarid cold. The experiment was laid out in a randomized complete block design in a factorial arrangement with three replications. Four bread wheat genotypes were used: 'Pishtaz,' 'DN-11', 'Sivand' and 'Marvdasht'. Treatments were two water regimes: control or well-watered (irrigation at 90 $\pm 5 \%$ field capacity in all stages of plant growth normally), and water deficit at vegetative growth stage. Soil moisture was about $50 \pm 5 \%$ of field capacity from the beginning of stem elongation to flowering stages; 31 to 59 of the Zadoks scale (Zadoks 1974). These four wheat genotypes were chosen because they were new modern genotypes with unknown biochemical and physiological characteristics. Some growing characteristics of the genotypes used in the experiments are shown in Table 1. The seeds of wheat genotypes were obtained from the Seed and Plant Improvement Institute, Agricultural and Natural Resources Research Center of Kermanshah, Iran. Seeds were sown in plastic pots with a diameter of $20 \mathrm{~cm}$ and height of $30 \mathrm{~cm}$, each filled with $3.5 \mathrm{~kg}$ o1:5 fertilized peat and soil. The soil physicochemical properties used in the experiment were: sand $17 \%$, silt $39 \%$, clay $44 \%$, pH 7.4, organic carbon $1.14 \mathrm{~g}$ $\mathrm{kg}^{-1}$, total $\mathrm{N} 0.098 \%$ and available $\mathrm{P}$ and $\mathrm{K} 8.0$ and $329 \mathrm{mg}$ $\mathrm{kg}^{-1}$, respectively. Ten seeds per pot were sown. Two week after their emergence, the number of the seedlings was reduced to five per pot.

\section{Leaf gas exchange}

The net photosynthetic rate, stomatal conductance, transpiration rate per leaf area, leaf temperature and substomatal $\mathrm{CO}_{2}$ concentration were measured using a portable photosynthesis system LI-6400 (LI-COR, Lincoln, USA) on the uppermost leaves on midday (09:00 to 12:00) at 20 days after water deficit. Photosynthetically active radiation was 1200 to $1600 \mu \mathrm{mol}$ photon $\mathrm{m}^{-2} \mathrm{~s}^{-1}$, ambient $\mathrm{CO}_{2}$ concentration was 380 to $400 \mathrm{ppm}$. Six leaves from three pots (two leaves per plant) were collected for measurement for each treatment at each time. Photosynthetic water use efficiency (PWUE) was calculated by dividing net photosynthetic rate by stomatal conductance (Ahmadi, Siosemardeh 2005).

\section{Total leaf area}

Total leaf area was measured with a leaf area meter (LI3000A, LI-COR, Lincoln NE, USA) at flowering stage. Ten plants (two pots) were collected for each treatment at measurement times.

\section{Grain yield and days to physiological maturity}

To estimate grain yield, ten plants were harvested at physiological maturity stage from each treatment (two pots). Number of days to physiological maturity was recorded.

\section{Water use efficiency and evapotranspiration efficiency}

At the end of the experiment, water use efficiency (WUE) and evapotranspiration efficiency were estimated as described by Ehdaie and Waines (1993) according to the following equations:

WUE $\left(\mathrm{kg} \mathrm{m}^{-3}\right)=[$ grain yield $(\mathrm{kg})] /[$ consumed water $\left.\left(\mathrm{m}^{3}\right)\right]$;

evapotranspiration efficiency $\left(\mathrm{kg} \mathrm{m}^{-3}\right)=[$ biomass $(\mathrm{kg})] /$ [consumed water $\left(\mathrm{m}^{3}\right)$ ].

\section{Statistical analysis}

The data collected was subjected to ANOVA to determine significant differences among treatments. SAS software (version 8.0) was used. The treatment means were compared by a Duncan Multiple Range test at 5\% significance level (Steel et al. 1997).

\section{Results}

\section{Photosynthesis and gas exchange variables}

Statistical analysis of gas exchange variables are presented in Table 2. The average net photosynthetic rate and gas exchange variables are listed in Fig. 1A-F. In this study, net photosynthetic rate decreased with water deficit stress, such that in the well-watered treatment, the net photosynthetic rate varied from 17.8 to $19.9 \mu \mathrm{mol} \mathrm{CO}_{2}$ $\mathrm{m}^{-2} \mathrm{~s}^{-1}$ whereas the range was 5.9 to $9.5 \mu \mathrm{mol} \mathrm{CO} \mathrm{m}^{-2} \mathrm{~s}^{-1}$

Table 1. Characteristics of genotypes used in the experiment. Source: Abdoli, Saeidi (2012)

$\begin{array}{lllll}\text { Genotypes } & \text { Grain yield } & \text { Physiological maturity } & \text { Plant height } & \text { Grain weight } \\ \text { 'Pishtaz' } & \text { High } & \text { Late maturing } & \text { Tall } & \text { High } \\ \text { 'Sivand' } & \text { High } & \text { Late maturing } & \text { Tall } & \text { High } \\ \text { 'Marvdasht' } & \text { Medium } & \text { Late maturing } & \text { Tall } & \text { Low } \\ \text { 'DN-11' } & \text { High } & \text { Early maturing } & \text { Medium } & \text { Medium }\end{array}$


Table 2. Analysis of variance (mean square) of the effect of water regime and genotypes on net photosynthesis rate (Pn), stomatal conductance (gs), transpiration rate (Tr), sub-stomatal $\mathrm{CO}_{2}$ concentration $(\mathrm{Ci})$, leaf temperature (Tl) and photosynthetic water use efficiency (PWUE). ns, ${ }^{*}$ and ${ }^{* *}$; non significant, significant at $5 \%$ and $1 \%$ levels of probability, respectively

\begin{tabular}{|c|c|c|c|c|c|c|c|}
\hline \multirow[t]{2}{*}{ Source of variation } & \multirow[t]{2}{*}{ df } & \multicolumn{6}{|c|}{ Mean squares } \\
\hline & & Pn & gs & $\operatorname{Tr}$ & $\mathrm{Ci}$ & $\mathrm{Tl}$ & PWUE \\
\hline Replication & 2 & $51.7 \mathrm{~ns}$ & $0.002 \mathrm{~ns}$ & $11.5^{*}$ & $3028 \mathrm{~ns}$ & $109^{* *}$ & $1745 \mathrm{~ns}$ \\
\hline Water regimes $(\mathrm{W})$ & 1 & $814^{\star *}$ & $0.087^{* *}$ & $101^{\star *}$ & $2563 \mathrm{~ns}$ & $73.2^{\star *}$ & $7340 \mathrm{~ns}$ \\
\hline Genotypes (G) & 3 & $8.61 \mathrm{~ns}$ & $0.003 \mathrm{~ns}$ & $1.65 \mathrm{~ns}$ & $1650 \mathrm{~ns}$ & $2.42 \mathrm{~ns}$ & $1293 \mathrm{~ns}$ \\
\hline $\mathrm{W} \times \mathrm{G}$ & 3 & $1.06 \mathrm{~ns}$ & $0.001 \mathrm{~ns}$ & $0.32 \mathrm{~ns}$ & $508 \mathrm{~ns}$ & $0.96 \mathrm{~ns}$ & $3290 \mathrm{~ns}$ \\
\hline Error & 14 & 24.1 & 0.003 & 3.07 & 1054 & 1.76 & 2668 \\
\hline CV (\%) & - & 36.8 & 31.8 & 33.7 & 20.6 & 3.54 & 36.8 \\
\hline
\end{tabular}

in water deficit conditions. A considerable reduction of $60.7 \%$ in net photosynthetic rate occurred due to water deficit (Fig. 1A). The top three genotypes retaining high net photosynthetic rate in non-stress condition were 'Pishtaz', 'Sivand' and 'Marvdasht' (19.0, 19.8 and $19.9 \mu \mathrm{mol} \mathrm{CO}_{2} \mathrm{~m}^{-2}$ $\mathrm{s}^{-1}$, respectively), while the lowest net photosynthetic rate under water deficit was in 'DN-11' by $5.9 \mu \mathrm{mol} \mathrm{CO} \mathrm{m}^{-2} \mathrm{~s}^{-1}$ (Fig. 1A).

The results showed significant differences in stomatal conductance between well-watered and water deficit conditions (Table 2). Under well-watered regime, 'Marvdasht' had the highest $\left(0.220 \mathrm{~mol} \mathrm{H}_{2} \mathrm{O} \mathrm{m}^{-2} \mathrm{~s}^{-1}\right)$ and under water deficit regime, 'Sivand' the lowest stomatal conductance $\left(0.040 \mathrm{~mol} \mathrm{H}_{2} \mathrm{O} \mathrm{m}^{-2} \mathrm{~s}^{-1}\right)$, but no significant differences were evident with the other genotypes (Fig. 1B).

The results clearly showed that water deficit stress at the vegetative growth stage decreased transpiration rate considerably. As expected, canopy temperature was significantly higher under water deficit conditions (Fig. 1C). Average leaf temperature of the genotypes in wellwatered condition was $35.7^{\circ} \mathrm{C}$, but under water deficit stress significantly increased to $39.2^{\circ} \mathrm{C}(9.8 \%$ increase compared to control; Fig. 1E). In general, genotypes and water deficit stress had no significant effects on sub-stomatal $\mathrm{CO}_{2}$ concentration and PWUE (Table 2; Fig. 1D,F).

\section{Agronomical and morpho-physiological characteristics}

Significant $(P<0.01)$ effect of water regime and genotype for area of leaves per plant were indicated (Table 3). The average leaf area of the genotypes in well-watered conditions was $14.8 \mathrm{~cm}^{2}$ plant $^{-1}$, while under water deficit this value significantly reduced to $8.93 \mathrm{~cm}^{2}$ plant $^{-1}$ (39.7\% lower than in the control; Fig. 2A). Furthermore, in the wellwatered treatment, 'Pishtaz' and 'Marvdasht' (12.9 and 13.8
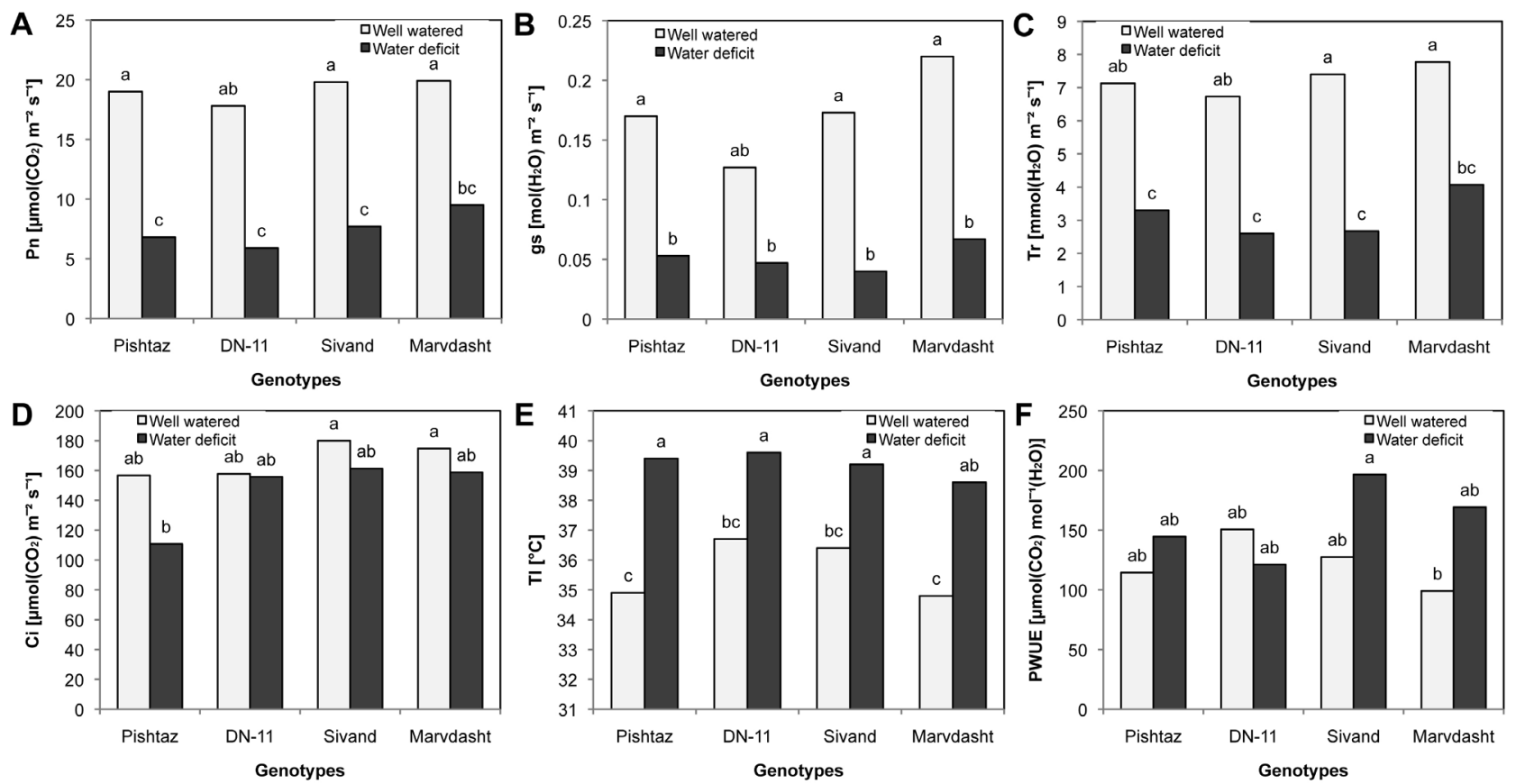

Fig. 1. Effect of water deficit on Pn, net photosynthesis rate (A); gs, stomatal conductance (B); Tr, transpiration rate (C); Ci, sub-stomatal $\mathrm{CO}_{2}$ concentration (D); Tl, leaf temperature (E) and PWUE, photosynthetic water use efficiency (F) of different wheat genotypes. Means followed by the same letters in each column are not significantly different at 5\% level, according to Duncan's Multiple Range test. 
Table 3. Analysis of variance (mean square) of the effect of water regimes and genotypes on grain yield, and some morphological and phonological traits. ns, ${ }^{\star}$ and ${ }^{* *}$; non significant, significant at $5 \%$ and $1 \%$ levels of probability, respectively

\begin{tabular}{|c|c|c|c|c|c|c|}
\hline \multirow[t]{2}{*}{ Source of variation } & \multirow[t]{2}{*}{ df } & \multicolumn{5}{|c|}{ Mean squares } \\
\hline & & Leaf area & $\begin{array}{c}\text { Days to } \\
\text { physiological } \\
\text { maturity }\end{array}$ & Grain yield & $\begin{array}{l}\text { Water use } \\
\text { efficiency }\end{array}$ & $\begin{array}{c}\text { Evapotranspiration } \\
\text { efficiency }\end{array}$ \\
\hline Replication & 2 & $3.49 \mathrm{~ns}$ & $45.7^{\star}$ & $0.124 \mathrm{~ns}$ & $0.007 \mathrm{~ns}$ & $0.073 \mathrm{~ns}$ \\
\hline Water regimes $(\mathrm{W})$ & 1 & $212^{\star *}$ & $1.04 \mathrm{~ns}$ & $170^{\star *}$ & $0.391^{\star *}$ & $1.03^{\star \star}$ \\
\hline Genotypes (G) & 3 & $19.5^{\star *}$ & $31.0 \mathrm{~ns}$ & $1.32 \mathrm{~ns}$ & $0.012 \mathrm{~ns}$ & $0.062 \mathrm{~ns}$ \\
\hline $\mathrm{W} \times \mathrm{G}$ & 3 & $8.90^{*}$ & $25.2 \mathrm{~ns}$ & $6.36^{* *}$ & $0.043^{*}$ & $0.082^{* *}$ \\
\hline Error & 14 & 2.65 & 9.45 & 0.54 & 0.005 & 0.021 \\
\hline CV (\%) & - & 13.6 & 3.15 & 12.6 & 17.4 & 16.1 \\
\hline
\end{tabular}

$\mathrm{cm}^{2}$ plant $^{-1}$, respectively) had the minimum and 'Sivand' $\left(17.3 \mathrm{~cm}^{2}\right.$ plant $\left.{ }^{-1}\right)$ had the maximum leaf area, as well as, under water deficit stress, 'DN-11' and 'Pishtaz' by 6.33 and $7.48 \mathrm{~cm}^{2}$ plant $^{-1}$, respectively had the lowest and 'Sivand' by $11.2 \mathrm{~cm}^{2}$ plant $^{-1}$ had the highest leaf area (Fig. 2A).

Genotypes and water deficit stress at the beginning of stem elongation to flowering stages had no significant effects on days to physiological maturity (Table 3; Fig. 2B).

The present results indicate that water deficit stress retards grain yield of the tested genotypes of wheat. In the well water treatment, grain yield of 'Marvdasht' was significantly lower than of other genotypes. In terms of grain yield production, except 'Marvdasht', there were no significant differences between other genotypes (Fig. 2C). Water deficit stress significantly reduced grain yield of the tested genotypes (54.4\%) compared to the control. The greatest reduction in grain yield occurred in ' $\mathrm{DN}-11$ ' and 'Sivand' genotypes and the lowest reduction in 'Marvdasht' and 'Pishtaz' genotypes (Fig. 2C).

Water deficit stress at vegetative stage showed negative effects on WUE and evapotranspiration efficiency (ratio of total dry weight to total water used) of wheat. Also on average there was 31.8 and $32.4 \%$ reduction in WUE and evapotranspiration efficiencies due to water deficit (Fig. $2 \mathrm{D}, \mathrm{E})$. Genotypic variation for WUE was significant under both water regimes (Fig. 2D). In the well-watered treatment WUE was highest in the 'DN-11' $\left(0.609 \mathrm{~kg} \mathrm{~m}^{-3}\right)$ and lowest in the 'Marvdasht' $\left(0.434 \mathrm{~kg} \mathrm{~m}^{-3}\right.$; Fig. 2D). However, under water deficit stress, the lowest and highest significant reductions in WUE and evapotranspiration efficiency were seen in 'Marvdasht' (13.0 and 22.0\%) and 'DN-11' (68.0 and $60.0 \%$ ), respectively (Fig. $2 \mathrm{D}, \mathrm{E}$ ).
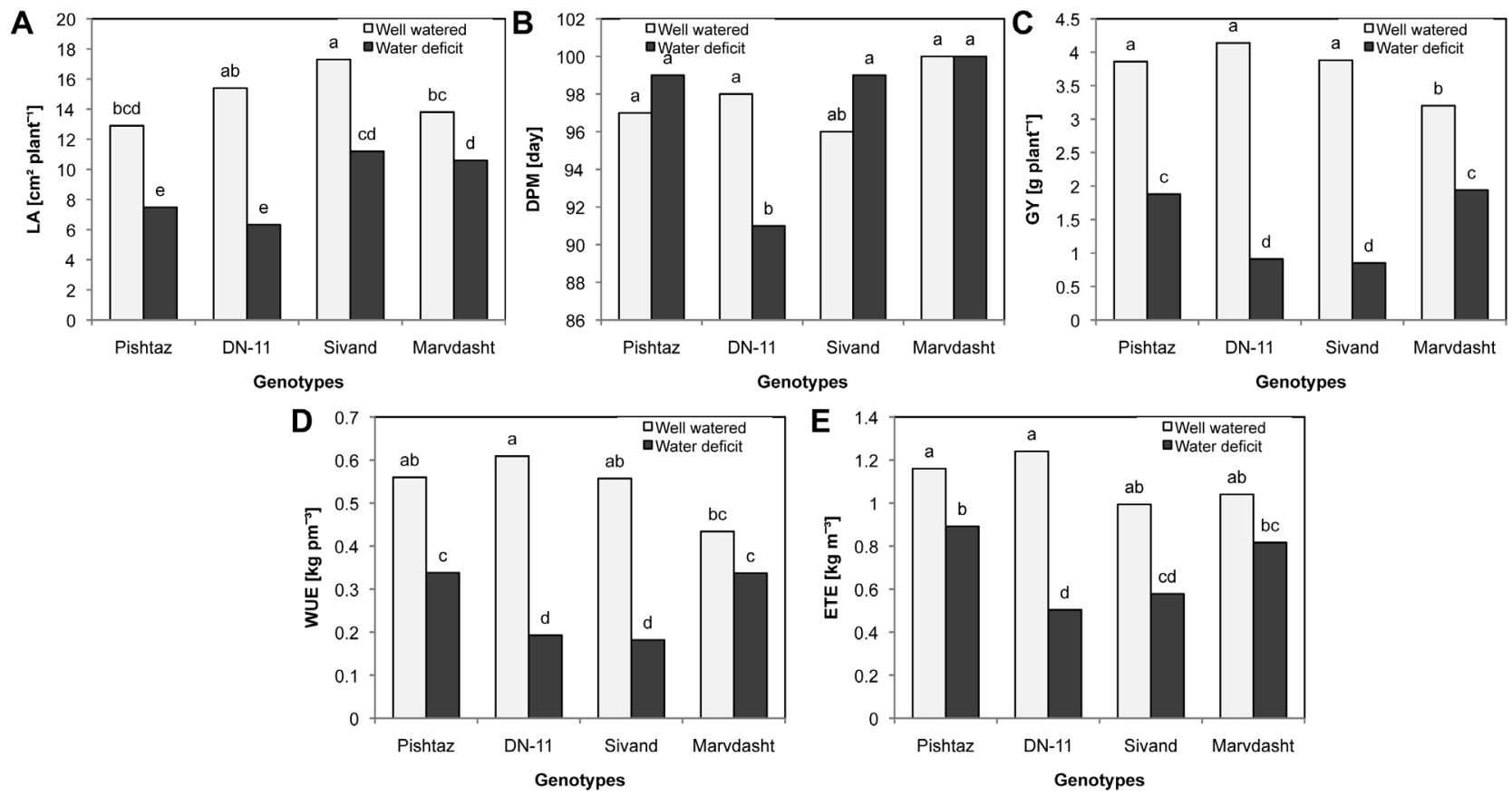

Fig. 2. Effect of water deficit on LA, leaf area (A); DPM, days to physiological maturity (B); GY, grain yield (C); WUE, water use efficiency (D) and ETE, evapotranspiration efficiency (E) of different wheat genotypes. Means followed by the same letters in each column are not significantly different at 5\% level, according to Duncan's Multiple Range test. 


\section{Discussion}

Drought, like other environmental stresses, affects many physiological, biochemical and metabolic processes in plants. Injury to drought includes reduction of growth, decrease in pigment and chlorophyll content, increase in $\mathrm{H}_{2} \mathrm{O}_{2}$, which causes lipid peroxidation, and consequently membrane injury and reduction of net photosynthetic rate (Mukherjee, Choudhuri 1983; Chaves et al. 2002). Persistence in net photosynthetic rate of genotypes in water deficit conditions may serve as good indicator of drought tolerance.

Results from this study show that photosynthesis and gas exchange variables declined when plants were subjected to water stress (Fig. $1 \mathrm{~A}-\mathrm{F}$ ). These results of the present study regarding gas exchange variables were similar with the results from other studies, which showed that limitation of irrigation at different crop growth stages considerably affects the gas exchange variables of wheat varieties (Chaves et al. 2002; Ahmadi, Siosemardeh 2005; Saeidi, Abdoli 2015; Cui et al. 2015). Stomatal closure is one of the earliest plant responses to water deficit, and causes decline in photosynthetic activity under water deficit conditions (Mafakheri et al. 2011; Azhand et al. 2015). Moreover, decreased net photosynthetic rate in plants under drought stress may be the result of reduction of Rubisco and PEP carboxylase activity under stress. The terminal drought stress reduced net photosynthetic rate, stomatal conductance, transpiration rate, chlorophyll $a$ and $b$ concentration, and chlorophyll $a / b$ ratio, and enhanced leaf temperature and sub-stomatal $\mathrm{CO}_{2}$ concentration (Saeidi, Abdoli 2015).

Water deficit stress caused increase of leaf temperature (7.7 to $12.9 \%$ ) of all genotypes (Fig. $1 \mathrm{E}$ ). In accordance with our results, Vaisnad and Talebi (2015) reported that water stress significantly increased canopy temperature in chickpea. Increase of canopy temperature during withholding of irrigation can be caused by reduced transpiration from leaves. In well-watered plants, the transpiration rate is higher and therefore, due to transpired water, the surface of leaves will be cooled (GonzalezDugo et al. 2005; Saeidi, Abdoli 2015; Khaki-Moghadam, Rokhzadi 2015). This agrees with the hypothesis that plants with low canopy temperature have a high photosynthesis rate and consequently more production (Hirayama et al. 2006). Under drought stress condition, sub-stomatal $\mathrm{CO}_{2}$ concentration in the leaf is decreased as a result of limited stomatal conductance but this variable did not significantly differ from thst under optimum water conditions (Fig. 1 D). However, it has been reported that water deficit stress at grain filling period can considerably increase substomatal $\mathrm{CO}_{2}$ concentration (Azhand et al. 2015; Saeidi; Abdoli 2015). Water deficit stress had no significant effect on PWUE (Table 2; Fig. 1 F). However, enhanced PWUE in wheat plants under post-anthesis water stress has been reported (Saeidi, Abdoli 2015).

In general, water deficit stress at the vegetative stage decreased leaf area (Fig. 2A). The major photosynthetic organ with respect to grain yield in wheat is flag leaf, which may be affected by water deficit during vegetative periods. It has been reported that growing cells of stressed leaves may not expand fully to the size under optimum conditiond, when drought reduces the number of cells produced per leaf, fewer are available for expansion in the post-treatment phase (Granier et al. 2000; Cui et al. 2015). This can be a reasonable explanation for the reduction of leaf area induced by water deficit stress during vegetative stages.

In this study, water stress significantly decreased grain yield (Fig. 2C). Water stress induced decrease in grain yield has been previously reported for several plant species, including synthetic hexaploid wheat (Pradhan et al. 2012), bread wheat (Inoue et al. 2004; Abdoli, Saeidi 2012), and chickpea (Vaisnad, Talebi 2015). In this case, mild water deficit during the vegetative period was noted to be useful and beneficial for grain yield in winter wheat (Kang et al. 2002; Cui et al. 2015) and spring wheat (Zhang et al. 2006), but the underlying mechanism has not been completely clarified. In our studies, water deficit during beginning of stem elongation to flowering stages decreased grain yield significantly. Attenuate yield in response to the water deficit treatment was probably related to the reduction in sink (reduced grain number and fertile florets) and source strengths (smaller leaf area, and reduction of photosynthetic activity) (Cui et al. 2015; Saeidi, Abdoli 2015).

Water deficit stress at the vegetative stage showed negative effects on WUE and evapotranspiration efficiency of different bread wheat cultivars (Fig. 2 D, E). WUE decreased under severe water deficit in 'Hab-Ahmar' and 'Sindy-2' genotypes, but was not affected in the other wheat genotypes (Boutraa et al. 2010). This decrease in WUE as a result of water stress was confirmed by a number of researchers using cultivars of winter bread wheat (Shangguan et al. 2000) and durum wheat (Boutraa et al. 2010). Commonly, management efforts are made to reduce water loss through pathways other than transpiration, increase leaf area index of crops, to increase level of absorbing sunlight, reduce evaporation from soil surface, and therefore raise WUE.

In general, the results showed that water deficit caused considerabe reduction of all photosynthetic parameters, compared to the well-watered treatment. Grain yield was diminished under water deficit treatment due to the decreased photosynthetic capacity of leaves. Hence, water deficit during vegetative periods is not beneficial for yield stability. Also, the results indicated the presence of a considerable amount of genotypic variation among the wheat accessions under water deficit stress. The wheat 'Marvdasht' genotype showed relatively more tolerance to drought at the vegetative growth stage with minimum reduction in photosynthesis rate, gas exchange variables and 
agronomic traits, compared with the other genotypes. We conclude that decreased photosynthetic capacity by water deficit during the vegetative growth period substantially lowers grain yield. Furthermore grain yield decreased due to the lowe leaf area and photosynthesis parameters under water deficit.

\section{Acknowledgements}

The authors would like to thank their colleagues in the Campus of Agriculture and Natural Resources, Faculty of Science and Agricultural Engineering, Department of Agronomy and Plant Breeding, Razi University, Kermanshah, Iran.

\section{References}

Abdoli M., Saeidi M. 2012. Using different indices for selection of resistant wheat cultivars to post anthesis water deficit in the west of Iran. Ann. Biol. Res. 3: 1322-1333.

Ahmadi A., Siosemardeh A. 2005. Investigation on the physiological basis of grain yield and drought resistance in wheat: Leaf photosynthetic rate, stomatal conductance and non-stomatal limitation. Int. J. Agric. Biol. 7: 807-811.

Azhand M., Saeidi M., Abdoli M. 2015. Evaluation of the relationship between gas exchange variables with grain yield in barley genotypes under terminal drought stress. Int. J. Biosci. 6: 366-374.

Boutraa T., Akhkha A., Al-Shoaibi A.A., Alhejeli A.M. 2010. Effect of water stress on growth and water use efficiency (WUE) of some wheat cultivars (Triticum durum) grown in Saudi Arabia. J. Taibah. Univ. Sci. 3: 39-48.

Chaves M.M., Oliveira M.M. 2004. Mechanisms underlying plant resilience to water deficits: prospects for water-saving agriculture. J. Exp. Bot. 55: 2365-238.

Chaves M.M., Pereira J.S., Maroco J., Rodrigues M.L., Ricardo C.P.P., Osorio M.L., Carvalho I., Faria T., Pinheiro C. 2002. How plants cope with water stress in the field? Photosynthesis and growth. Ann. Bot. 89: 907-916.

Cui Y., Tian Z., Zhang X., Muhammad A., Han H., Jiang D., Cao W., Dai T. 2015. Effect of water deficit during vegetative growth periods on post-anthesis photosynthetic capacity and grain yield in winter wheat (Triticum aestivum L.). Acta Physiol. Plant. 37: 1-10.

Ehdaie B., Waines J.G. 1993. Variation in water use efficiency and its components in wheat: I. Well-watered pot experiment. Crop. Sci. 33: 294-299.

Gonzalez-Dugo M.P., Moran M.S., Mateos L., Bryant R. 2005. Canopy temperature variability as an indicator of crop water stress severity. Irrig. Sci. 24: 233-240.

Gourdji S.M., Mathews K.L., Reynolds M., Crossa J., Lobell D.B. 2013. An assessment of wheat yield sensitivity and breeding gains in hot environments. Proc. Royal Soc. B Biol. Sci. 280: $1-8$.

Granier C., Turc O., Tardieu F. 2000. Co-ordination of cell division and tissue expansion in sunflower, tobacco, and pea leaves: dependence or independence of both processes? J. Plant. Growth. Regul. 19: 45-54.

Hirayama M., Wada Y., Nemoto H. 2006. Estimation of drought tolerance based on leaf temperature in upland rice breeding. Breed. Sci. 56: 47-54.

Inoue T., Inanaga S., Sugimoto Y., El Siddig K. 2004. Contribution of pre-anthesis assimilates and current photosynthesis to grain yield, and their relationships to drought resistance in wheat cultivars grown under different soil moisture. Photosynthetica 42: 99-104.

Kang S., Zhang L., Liang Y., Hu X., Cai H., Gu B. 2002. Effects of limited irrigation on yield and water use efficiency of winter wheat in the Loess Plateau of China. Agr. Water. Manage. 55: 203-216.

Khaki-Moghadam A., Rokhzadi A. 2015. Growth and yield parameters of safflower (Carthamus tinctorius) as influenced by foliar methanol application under well-watered and water deficit conditions. Environ. Exp. Biol. 13: 93-97.

Lawlor D.W., Tezara W. 2009. Causes of decreased photosynthetic rate and metabolic capacity in water-deficient leaf cells: a critical evaluation of mechanisms and integration of processes. Ann. Bot. 103: 561-579

Mafakheri A., Siosemardeh A., Bahramnejad B., Struik P.C., Sohrabi Y. 2011. Effect of drought stress and subsequent recovery on protein, carbohydrate contents, catalase and peroxidase activities in three chickpea (Cicer arietinum) cultivars. Austr. J. Crop. Sci. 5: 1255-1260.

Mukherjee S.P., Choudhuri M.A. 1983. Implications of water stress-induced changes in the leaves of indigenous ascorbic acid and hydrogen peroxidase in Vigna seedlings. Plant. Physiol. 58: 166-170.

Powell N., Ji X., Ravash R., Edlington J., Dolferus R. 2012. Yield stability for cereals in a changing climate. Funct. Plant. Biol. 39: 539-552.

Pradhan G.P., Prasad P.V., Fritz A.K., Kirkham M.B., Gill B.S. 2012. Effects of drought and high temperature stress on synthetic hexaploid wheat. Funct. Plant. Biol. 39: 190-198.

Saeidi M., Abdoli M. 2015. Effect of drought stress during grain filling on yield and its components, gas exchange variables, and some physiological traits of wheat cultivars. J. Agr. Sci. Tech. 17: 885-898.

Shangguan Z.P., Shao M.A., Dyckmans, J. 2000. Nitrogen nutrition and water stress effects on leaf photosynthetic gas exchange and water use efficiency in winter wheat. Environ. Exp. Bot. 44: 141-149.

Steel R.G.D., Torrie J.H., Dickey D. 1997. Principles and Procedures of Statistics: Abiometrical Approach. 3rd Ed. McGraw Hill Book Co., New York.

Talebi R., Ensafi M.H., Baghebani N., Karami E., Mohammadi K.H. 2013. Physiological responses of chickpea (Cicer arietinum) genotypes to drought stress. Environ. Exp. Biol. 11: 9-15.

Vaisnad S., Talebi R. 2015. Salicylic acid-enhanced morphological and physiological responses in chickpea (Cicer arietinum) under water deficit stress. Environ. Exp. Biol. 13: 109-115.

Zadoks J.C., Chang T.T., Konzak B.F. 1974. A decimal code for growth stages of cereals. Weed Res. 14: 415-421.

Zhang B., Li F., Huang G., Cheng Z., Zhang Y. 2006. Yield performance of spring wheat improved by regulated deficit irrigation in an arid area. Agr. Water. Manage. 79: 28-42.

Zhang X.Y., Pei D., Hu C.S. 2003. Conserving groundwater for irrigation in the North China Plain. Irrig. Sci. 21: 159-166. 